\title{
The effect of cisatracurium infusion on the energy expenditure of critically ill patients: an observational cohort study
}

\author{
W. A. C. Koekkoek', Y. A. Menger², F. J. L. van Zanten, D. van Dijk and A. R. H. van Zanten ${ }^{4 *}$
}

\begin{abstract}
Background: Both overfeeding and underfeeding of intensive care unit (ICU) patients are associated with worse outcomes. A reliable estimation of the energy expenditure (EE) of ICU patients may help to avoid these phenomena. Several factors that influence EE have been studied previously. However, the effect of neuromuscular blocking agents on EE, which conceptually would lower EE, has not been extensively investigated.

Methods: We studied a cohort of adult critically ill patients requiring invasive mechanical ventilation and treatment with continuous infusion of cisatracurium for at least $12 \mathrm{~h}$. The study aimed to quantify the effect of cisatracurium infusion on $\mathrm{EE}$ (primary endpoint). EE was estimated based on ventilator-derived $\mathrm{VCO}_{2}$ (EE in $\mathrm{kcal} /$ day $=\mathrm{VCO}_{2} \times$ 8.19). A subgroup analysis of septic and non-septic patients was performed. Furthermore, the effects of body temperature and sepsis on EE were evaluated. A secondary endpoint was hypercaloric feeding (>110\% of EE) after cisatracurium infusion.

Results: In total, 122 patients were included. Mean EE before cisatracurium infusion was $1974 \mathrm{kcal} /$ day and 1888 $\mathrm{kcal} /$ day after cisatracurium infusion. Multivariable analysis showed a significantly lower EE after cisatracurium infusion ( $M D-132.0 \mathrm{kcal}(95 \% \mathrm{Cl}-212.0$ to $-52.0 ; p=0.001)$ in all patients. This difference was statistically significant in both sepsis and non-sepsis patients $(p=0.036$ and $p=0.011)$. Non-sepsis patients had lower EE than sepsis patients (MD $-120.6 \mathrm{kcal} ; 95 \% \mathrm{Cl}-200.5$ to $-40.8, p=0.003$ ). Body temperature and $\mathrm{EE}$ were positively correlated (Spearman's rho $=0.486, p<0.001$ ). Hypercaloric feeding was observed in 7 patients.

Conclusions: Our data suggest that continuous infusion of cisatracurium in mechanically ventilated ICU patients is associated with a significant reduction in EE, although the magnitude of the effect is small. Sepsis and higher body temperature are associated with increased EE. Cisatracurium infusion is associated with overfeeding in only a minority of patients and therefore, in most patients, no reductions in caloric prescription are necessary.
\end{abstract}

Keywords: Energy expenditure, Overfeeding, Neuromuscular blocking agent

\section{Background}

Targeting optimal nutrition concerning energy goals is essential in critically ill patients, as both underfeeding and overfeeding have been associated with increased morbidity and mortality [1]. Ideally, the target is based on energy expenditure (EE). However, due to the pathophysiological response to critical illness, iatrogenic interventions, and differences in body composition, EE is

\footnotetext{
*Correspondence: zantena@zgv.nl

'Department of Intensive Care Medicine, Gelderse Vallei Hospital, Willy Brandtlaan 10, 6716 RP Ede, The Netherlands

Full list of author information is available at the end of the article
}

highly variable in and between critically ill patients [2]. Frequent monitoring of EE may circumvent this problem and help to adjust the optimal amount of calories on an individual basis. At present, indirect calorimetry is considered the gold standard. However, frequently, this technique is not available and often unfeasible [3].

To optimize nutritional targets without frequent monitoring of EE, it is essential to know which factors are associated with either an increase or decrease in EE.

Specific conditions expected to influence EE have been studied such as sepsis [4-6], burns [4, 7], trauma [4, 8], cerebrovascular accidents [4,9], pregnancy [10], body 
temperature [4], administration of sedatives [11], and therapeutic hypothermia [4, 12]. An increased EE has been reported in patients with sepsis, trauma, burns, fever, and pregnancy. Therapeutic hypothermia and the administration of sedatives are associated with a decrease in EE [4]. However, limited information is available on the effects of neuromuscular blocking agents (NMBAs) on EE. Furthermore, it is not known whether NMBA administration affects the EE in sepsis patients similarly compared with non-sepsis patients and in relation to the baseline temperature.

This study aimed to quantify the effect of cisatracurium infusion on EE of adult critically ill patients. Also, we analyzed the effects of body temperature and sepsis on EE. Secondary endpoint was hypercaloric feeding as a consequence of muscle relaxation.

\section{Materials and methods}

We performed a retrospective observational study in patients treated with cisatracurium at the mixed medicalsurgical adult intensive care unit of the Gelderse Vallei Hospital, Ede, The Netherlands, between January 1, 2011, and October 31, 2016. Patients were included when they met with the following inclusion criteria: adult critically ill patients ( $\geq 18$ years) requiring invasive mechanical ventilation and treatment with cisatracurium for at least $12 \mathrm{~h}$.

Exclusion criteria were pregnancy, hypothermia induced by therapeutic temperature management, burns, and malignant hyperthermia because these conditions have a substantial effect on EE. Patients were also excluded when data on $\mathrm{VCO}_{2}$ were incomplete. In patients with multiple ICU admissions during the study period, data from readmissions were excluded. An ICU admission was considered readmission when the patient was admitted within 6 months from the primary ICU admission.

\section{Administration of cisatracurium}

Cisatracurium is the NMBA of choice for sustained neuromuscular blockade during critical illness in Gelderse Vallei Hospital. Cisatracurium was administered when indicated according to the international clinical practice guidelines for the sustained neuromuscular blockade in the adult critically ill patient [13]. An infusion was started at doses of $3 \mu \mathrm{g} / \mathrm{kg}$ per minute and then adjusted by assessment of the train-of-four (TOF) using a peripheral nerve stimulator (TOF-watch ${ }^{\circ} \mathrm{S}$, Dublin, Ireland). According to the hospital protocol, TOF measurements were performed every hour, and dosage adjustments were made to achieve a TOF level of 1 or lower. The electrodes of the TOF-watch ${ }^{\circ}$ were placed on the other wrist daily to prevent skin lesions.

\section{Outcome measures}

The primary endpoint was the total EE, expressed as $\mathrm{kcal} /$ day, which was measured before and during cisatracurium infusion. Indirect calorimetry was not routinely available during the study period. EE was, therefore, estimated by an adjusted version of Weir's equation using the ventilator-derived $\mathrm{VCO}_{2} \quad\left(\mathrm{EEVCO}_{2}\right) . \quad \mathrm{EEVCO}_{2}=$ $3.941 \times \mathrm{VCO}_{2}(\mathrm{~L} / \mathrm{min})$ / respiratory quotient $+1.11 \times$ $\mathrm{VCO}_{2}(\mathrm{~L} / \mathrm{min}) \times 1440$. The respiratory quotient was considered to be a fixed value of 0.86 [14-16]. The mechanical ventilator measured the VCO2 (Hamilton-S1, Hamilton Medical AG, Bonaduz, Switzerland), and every minute, data are automatically sent to our electronic patient data management system (MetaVision; iMDsoft MetaVision $^{\circ}$, Tel Aviv, Israel). For each patient, the $\mathrm{VCO}_{2}$ was collected during the $12 \mathrm{~h}$ before and during the $12 \mathrm{~h}$ after the start of cisatracurium infusion. When patients were not admitted to the ICU $12 \mathrm{~h}$ before the start of cisatracurium infusion, the parameters of the available hours were used. The $\mathrm{EEVCO}_{2}$ was calculated every $2 \mathrm{~h}$ using the mean $\mathrm{VCO}_{2}$ measurements from the previous $2 \mathrm{~h}$.

Secondary endpoint was hypercaloric feeding (>110\% of EE) after cisatracurium infusion. We also evaluated ICU length of stay (LOS) and in-hospital mortality in patients receiving hypercaloric versus regular or hypocaloric feeding.

\section{Calculation of nutritional goals}

The World Health Organization/Food and Agricultural Organization of the United Nations (WHO/FAO) formulas were used to calculate caloric and protein targets by our computerized feeding protocol [17]. According to $\mathrm{BMI}$, the actual $(\mathrm{BMI}<27)$, corrected (BMI 27-30; regression to BMI of 27), or ideal body weight (BMI > 30; regression to BMI 21 in women and BMI 22.5 in men) was used. An addition to the resting EE (REE) of $20 \%$ was used to correct for disease activity [18].

\section{Data collection}

Most parameters were routinely collected into an extensive ICU database during standard clinical care. Data extraction was performed using SAS Enterprise Guide queries (version 7.12HF1) searching our Patient Data Management System (MetaVision; iMDsoft MetaVision ${ }^{\circ}$, Tel Aviv, Israel, and neoZIS ${ }^{\circ}$, Electronic Medical Record, MI Consultancy, Katwijk, The Netherlands). Data to calculate the Charlson Comorbidity Index (CCI) [19] were obtained from the quality management system for hospital mortality registration. Data verification was performed manually. Collected data were de-identified and stored on a secure hospital computer. There were no identifiable paper documents. 


\section{Data analysis and statistical considerations}

Descriptive data are reported as means and standard deviation $(\mathrm{SD})$ or median and interquartile range in case of skewed distributions, or as frequencies and percentages when appropriate. For the primary analysis, comparing the EE before and after cisatracurium infusion, a general linear mixed model analysis for repeated measures was performed with an autoregressive covariance structure. In this analysis, we corrected for body temperature, sedative and noradrenaline dosages, $\mathrm{pH}, \mathrm{PEEP}$, and $\mathrm{FiO}_{2}$ and repeated measurements.

We performed a subgroup analysis of septic and nonseptic patients. We also evaluated the effects of body temperature on EE with the Pearson or Spearman rank correlation tests. The effects of sepsis on EE were analyzed through general linear mixed models, correcting for the following confounders: cisatracurium, temperature, NUTRIC score, gender, BMI, admission type, and repeated effects. Finally, we evaluated the effect of hypercaloric feeding vs. normocaloric and hypocaloric feeding on in-hospital mortality and ICU length of stay (LOS) by chi-square test and one-way ANOVA, respectively. A $p$ value of $<0.05$ was considered statistically significant.
The data analyses were performed using IBM corp. SPSS statistics for Windows (version 24.0, released 2015 New York, USA).

\section{Results}

\section{Patients}

During the study period, 4247 patients were admitted to the ICU, of which 179 received cisatracurium for at least $12 \mathrm{~h}$ and therefore were eligible for inclusion. We excluded 57 patients according to the exclusion criteria. In total, 122 patients were enrolled in this study (Fig. 1).

Baseline characteristics and nutritional parameters are shown in Tables 1, 2, and 3. The median age was 65.5 years, and $36.1 \%$ were female. The median SOFA and APACHE II scores on admission were 8 and 22, respectively. Most patients were septic (58.2\%) and admitted to the ICU because of medical reasons (73\%). A median ICU and hospital LOS of 15 and 23 days were found. The in-hospital mortality was $28.7 \%$.

\section{Primary outcome}

The mean EE was $1974 \mathrm{kcal} /$ day before cisatracurium infusion (= control period) and $1888 \mathrm{kcal} /$ day during cisatracurium infusion resulting in a mean difference of

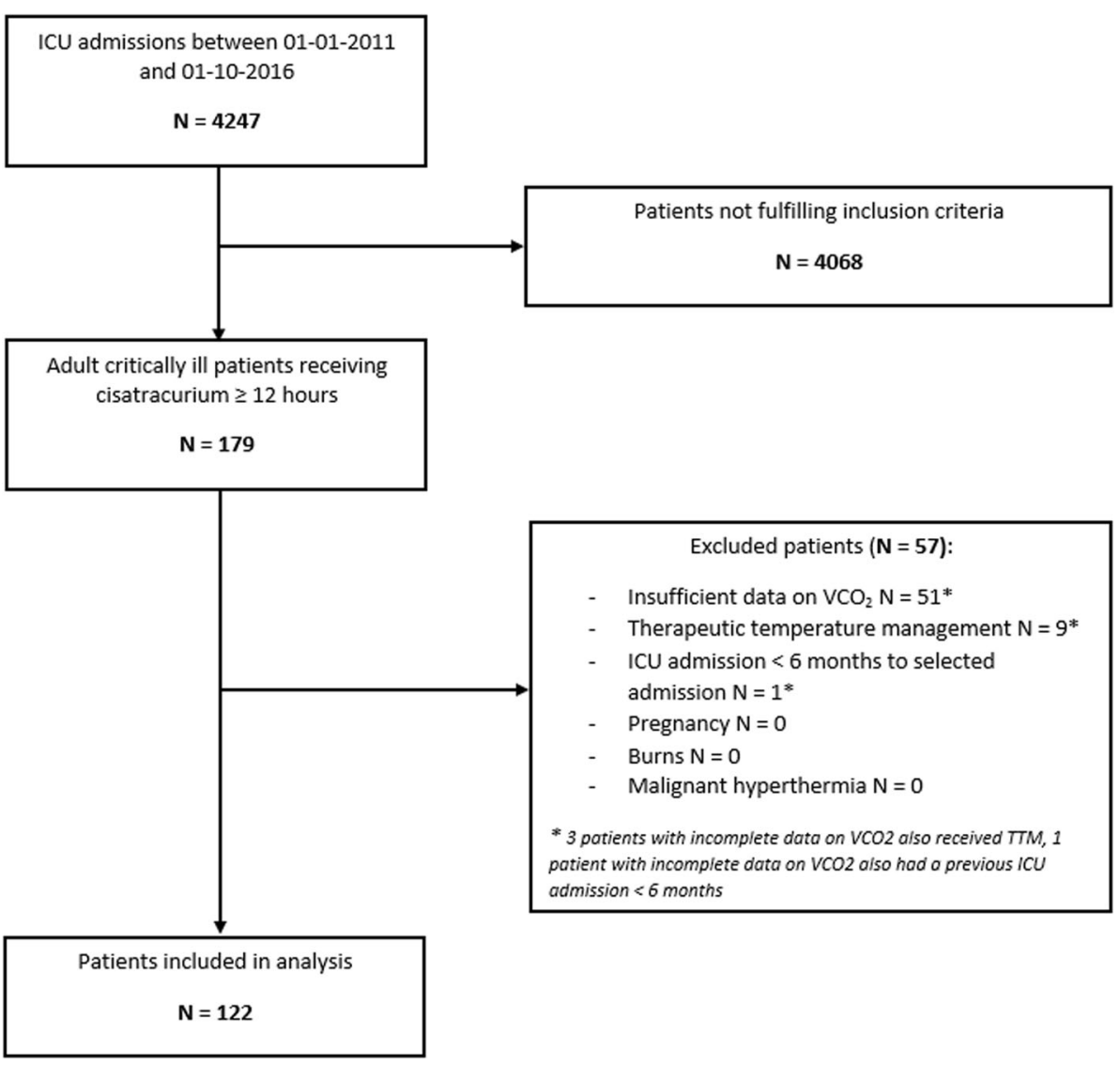

Fig. 1 Flowchart 
Table 1 Baseline characteristics

\begin{tabular}{|c|c|c|}
\hline & & Total $(n=122)$ \\
\hline Gender (female) & $N(\%)$ & $44(36.1)$ \\
\hline Age (years) & Median [IQR] & $66[55-73]$ \\
\hline BMI on admission $\left(\mathrm{kg} / \mathrm{m}^{2}\right)$ & Median $[\mathrm{IQR}]$ & $27.6[24.0-31.0]$ \\
\hline - Malnourished $(<18.5)$ & $N(\%)$ & $3(2.5)$ \\
\hline - Normal (18.5-24.9) & & $33(27.0)$ \\
\hline - Overweight (25-29.9) & & $44(36.1)$ \\
\hline - Obese (30-34.9) & & $26(21.3)$ \\
\hline - Morbidly obese (> 35) & & $16(13.1)$ \\
\hline Admission type & $N(\%)$ & \\
\hline - Medical & & $89(73.0)$ \\
\hline - Emergency surgery & & $16(13.1)$ \\
\hline - Elective surgery & & $17(13.9)$ \\
\hline Sepsis & $N(\%)$ & $72(59.0)$ \\
\hline Charlson Comorbidity Index & Median [IQR] & $4[2-5]$ \\
\hline SOFA score on admission & Median [IQR] & $8[5-9.5]$ \\
\hline APACHE II score on admission & Median [IQR] & $21.5[19-26.25]$ \\
\hline ICU length of stay (days) & Median [IQR] & $15[8-26.5]$ \\
\hline Hospital length of stay (days) & Median [IQR] & 23 [12-42] \\
\hline In-hospital mortality & $N(\%)$ & $36(29.5)$ \\
\hline
\end{tabular}

$B M I$ body mass index, IQR interquartile range, SOFA Sequential Organ Failure Assessment, APACHE acute physiology and chronic health evaluation, ICU intensive care unit

- 85.9 kcal (95\% CI -151.8 to $-20.0 ; p=0.011)$. After correction for body temperature, sedative and noradrenalin dosages, $\mathrm{pH}, \mathrm{PEEP}$, and $\mathrm{FiO}_{2}$ in mixed model multivariable analysis, the significant treatment effect of cisatracurium on EE persisted, with a mean difference of - $132.0 \mathrm{kcal}(95 \% \mathrm{CI}-212.0$ to $-52.0 ; p=0.001)$. Cisatracurium significantly lowered EE by $6.6 \%$ (95\% CI $2.6-$ 10.6\%). The results are depicted in Fig. 2.

\section{Subgroup analysis of sepsis patients}

In the subgroup of sepsis patients, cisatracurium reduced EE from $2058 \mathrm{kcal} /$ day to $1932 \mathrm{kcal} /$ day (mean difference of $-125.7 \mathrm{kcal}$; $95 \% \mathrm{CI}-243.0$ to $-8.4 ; p=$
Table 3 Nutritional parameters

\begin{tabular}{lll}
\hline & & Total $(n=122)$ \\
\hline NUTRIC score at admission & Median [IQR] & $6[4-7]$ \\
- Low risk (0-4 points) & $N(\%)$ & $35(29.9)$ \\
- High risk (5-9 points) & $N(\%)$ & $82(71.1)$ \\
Nutritional route ${ }^{\text {a }}$ & $N(\%)$ & \\
- Enteral & & $91(91.9)$ \\
- Parenteral & & $6(6.1)$ \\
- Both & & $2(2.0)$ \\
Average caloric intake (kcal/day) $)^{b}$ & Mean $( \pm S D)$ & $831(612)$ \\
\hline
\end{tabular}

NUTRIC Nutrition Risk in Critically ill [20], IQR interquartile range, $S D$ standard deviation

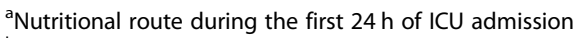

${ }^{\mathrm{b}}$ Average caloric and protein intake during the first day of cisatracurium administration (kcal/day)

0.036). In the subgroup of non-sepsis patients, cisatracurium reduced EE from $1932 \mathrm{kcal} /$ day to $1795 \mathrm{kcal} /$ day (mean difference $-137.2 \mathrm{kcal}$; $95 \%$ CI -243.0 to -31.4 ; $p=0.011$ ). In both analyses, adjustment for body temperature, sedative and noradrenaline dosages, $\mathrm{pH}$, PEEP, and $\mathrm{FiO}_{2}$ were performed.

\section{Effect of body temperature on EE}

A significant non-linear positive association between body temperature and EE was found (Spearman's rho = 0.486, $p<0.001$; Fig. 3).

\section{Effect of sepsis on EE}

Mean EE was $1805 \mathrm{kcal}$ (95\% CI 1721-1888) in nonseptic patients and $1909 \mathrm{kcal}$ (95\% CI 1838-1978) in septic patients $(p=0.062)$. In mixed-model multivariable analysis, a significantly lower EE was observed in nonseptic patients than in septic patients (mean difference - $120.6 \mathrm{kcal}, 95 \% \mathrm{CI}-200.5$ to $-40.8 ; p=0.003$ ).

\section{Hypercaloric feeding}

Only seven patients $(5.7 \%)$ received $>110 \%$ of their caloric target (estimated by $\mathrm{EEVCO}_{2}$ ) on the first day of cisatracurium infusion. Twenty patients (16.4\%) received between 80 and $110 \%$ of their caloric target, while 95

Table 2 Baseline characteristics before and after cisatracurium administration

\begin{tabular}{|c|c|c|c|c|}
\hline & & Before cisatracurium $(n=122)$ & After cisatracurium $(n=122)$ & $p$ value \\
\hline PEEP $\left(\mathrm{cmH}_{2} \mathrm{O}\right)$ & Mean \pm SD & $9.8 \pm 3.0$ & $10.6 \pm 3.9$ & 0.012 \\
\hline $\mathrm{FiO}_{2}(\%)$ & Median [IQR] & $49[40-59]$ & $44.5[36-55]$ & 0.008 \\
\hline Noradrenalin ( $\mu \mathrm{g} / \mathrm{kg} / \mathrm{min})$ & Mean \pm SD & $0.16 \pm 0.64$ & $0.33 \pm 1.25$ & 0.178 \\
\hline Propofol (mg/h) & Mean \pm SD & $44.9 \pm 73.1$ & $42.2 \pm 70.8$ & 0.570 \\
\hline Midazolam (mg/h) & Mean \pm SD & $7.5 \pm 5.3$ & $9.0 \pm 5.8$ & $<0.001$ \\
\hline Morphine (mg/h) & Mean \pm SD & $1.2 \pm 1.3$ & $1.5 \pm 1.4$ & $<0.001$ \\
\hline $\mathrm{pH}$ & Mean \pm SD & $7.31 \pm 0.11$ & $7.32 \pm 0.10$ & 0.600 \\
\hline TOF & Median [IQR] & NA & $0[0-1]$ & NA \\
\hline
\end{tabular}

PEEP positive end-expiratory pressure, $\mathrm{FiO}_{2}$ fraction of inspired oxygen, $\mathrm{TOF}$ train of four, $\mathrm{NA}$ not applicable 


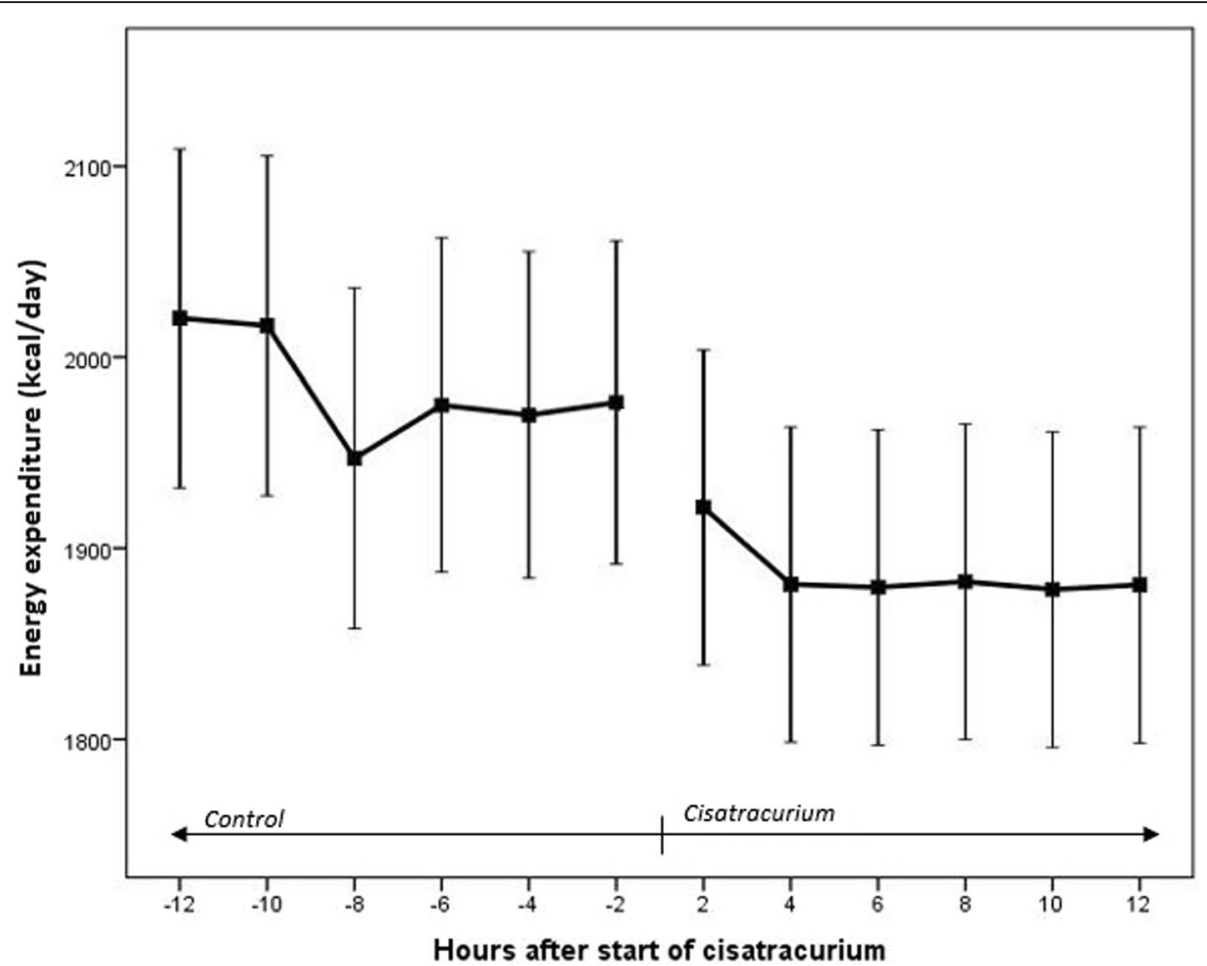

Fig. 2 Energy expenditure before and during continuous cisatracurium infusion

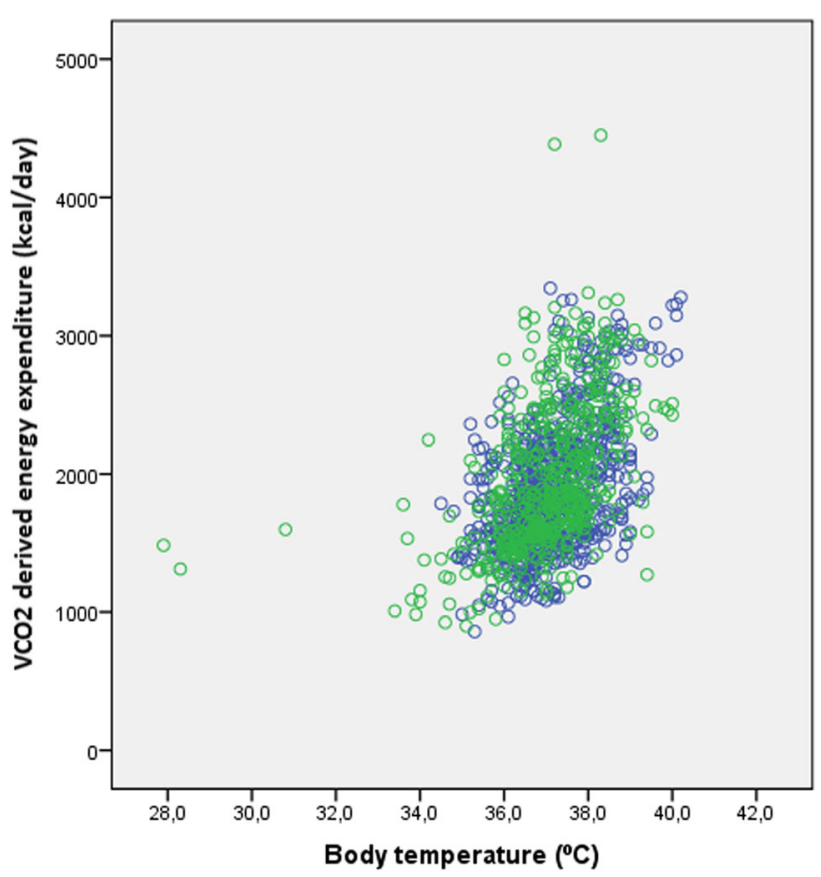

O Cisatracurium

Control

Fig. 3 Association between body temperature and energy expenditure 
patients (77.9\%) were fed hypocalorically $(<80 \%$ of caloric target). Because of the small number of patients with hypercaloric intake, no associations between hypercaloric intake and ICU LOS or mortality were calculated.

\section{Discussion}

We studied the effect of cisatracurium infusion on EE in a cohort of 122 adult critically ill patients. Cisatracurium infusion lowered $\mathrm{EE}$ as estimated by the $\mathrm{VCO}_{2}$ method by $6.6 \%$.

NMBAs act by interfering with the binding of acetylcholine to the motor endplate in the synaptic cleft of the neuromuscular junction, thereby ultimately preventing muscle contraction. Indications for the continuous infusion of NMBAs during critical illness comprise severe acute respiratory distress syndrome (ARDS) $\left(\mathrm{PaO}_{2} / \mathrm{FiO}_{2}\right.$ $<150$ ), overt shivering during therapeutic hypothermia, and other life-threatening situations associated with profound hypoxemia, respiratory acidosis, or hemodynamic compromise in case of failure of other measures such as deep sedation [13]. Cisatracurium is one of the most widely used NMBAs for continuous infusion as it can also be used in patients with hepatic or renal insufficiency [21].

Due to the blocking of muscle contractions and as a consequence of the subsequent lower muscular heat production, NMBAs should conceptually reduce EE. However, this hypothesis has not been studied in ICU patients with the previously described indications for the use of continuous NMBA infusion. Overall, only one earlier study has evaluated the effects of NMBAs on EE in adults, reporting a significant increase in EE of $18.6 \%$ after discontinuation of pancuronium in patients with severe head injury [22]. Additionally, one study investigated the effects of NMBA infusion (vecuronium, pancuronium, and atracurium) in 20 critically ill children reporting a significant reduction of $10.3 \%$ of EE $1 \mathrm{~h}$ after infusion of NMBAs [23].

\section{Effect of body temperature on EE}

We observed a non-linear positive association between body temperature and EE. Four small previous studies reported an association between body temperature and EE in critically ill patients $[4,24,25]$. A reduction of $6.6 \%$ of $\mathrm{EE}$ per $1{ }^{\circ} \mathrm{C}$ decrease at temperatures below $36^{\circ} \mathrm{C}$ and an increase of $8.2 \%$ per $1{ }^{\circ} \mathrm{C}$ at temperatures above $37^{\circ} \mathrm{C}$ have been reported $[24,25]$.

\section{Effect of sepsis on EE}

We observed a higher EE in septic patients than in nonseptic patients. This was in line with our expectations based on previous studies in which EE in septic patients was 102-198\% of EE in non-septic patients [4].
However, a recent observational study in 205 patients found no differences in EE between septic and nonseptic patients (1434 vs. $1430 \mathrm{kcal} /$ day) [20].

\section{Strengths and weaknesses}

This is the largest cohort of critically ill patients in which the effects of NMBAs on EE have been studied. The effects of NMBAs, especially cisatracurium, in this specific patient population have not been studied before. A large number of patient variables were available with few missing data, providing enough data to perform rigorous multivariable and repeated measure analyses.

However, our study has several limitations. Indirect calorimetry was not routinely available during the study period. Therefore, EE was calculated using $\mathrm{VCO}_{2}$ obtained from the mechanical ventilator. Calculation of $\mathrm{EE}$ from $\mathrm{VCO}_{2}$ has been demonstrated to be more accurate than predictive equations, but less than indirect calorimetry. Finally, limitations related to the retrospective design may potentially have introduced bias and residual confounding.

\section{Clinical implications}

As cisatracurium reduces $\mathrm{EE}$, reduction of caloric intake after the start of NMBAs should be considered, especially in those patients that are on full feeding or considered to reach this target soon, because they are at risk of hypercaloric feeding and associated harm. Before we designed the study, we expected, due to the drop in EE induced by the NMBA, that some of the patients would be overfed. Based on the results, we noticed that a reduction of EE by NMBA could induce an almost $10 \%$ overfeeding risk in individual patients. In daily practice, this did not occur as the patients were not on nutrition target. Thus, for most patients, adjustment may not be necessary as in our analysis the reduction of EE found was only $6.6 \%$ and hypercaloric feeding was only present in $5.7 \%$, while most other patients were fed (77.9\%) hypocalorically after initiation of cisatracurium infusion.

Although not the focus of our present study, it should be noted that the recent ROSE trial, studying the effect of early neuromuscular blockade (48-h continuous infusion of cisatracurium) with concomitant heavy sedation, compared with usual care, did not result in a significant mortality difference at 90 days in patients with moderate to severe acute respiratory distress syndrome in contrast to an earlier RCT $[26,27]$. This trial was stopped early at the second interim analysis for futility. This study may lead to reevaluation of the use of NMBAs in severe respiratory failure.

\section{Conclusions}

Our data suggest that continuous infusion of cisatracurium in mechanically ventilated ICU patients is associated 
with a significant reduction in $\mathrm{EE}$ as estimated by the $\mathrm{VCO}_{2}$ method, although the magnitude of the effect is small. Sepsis and higher body temperature are associated with increased EE. Cisatracurium infusion is associated with overfeeding in only a minority of patients, and therefore, in most patients no reductions in caloric prescription are necessary.

\section{Abbreviations}

APACHE: Acute physiology and chronic health evaluation; ARDS: Acute respiratory distress syndrome; BMI: Body mass index; $\mathrm{CCl}$ : Charlson Comborbidity Index; EE : Energy expenditure; $\mathrm{EEVCO}_{2}$ : Energy expenditure calculated from ventilator-derived $\mathrm{VCO}_{2} ; \mathrm{FAO}$ : Food and Agriculture Organization; $\mathrm{FiO}_{2}$ : Fraction of inspired oxygen; ICU: Intensive care unit; LOS: Length of stay; NMBA: Neuromuscular blocking agent; NUTRIC: Nutrition Risk in Critically ill; PEEP: Positive end-expiratory pressure; SD: Standard deviation; SOFA: Sequential Organ Failure Assessment; TOF: Train of four; WHO: World Health Organization

\section{Acknowledgements}

The authors wish to thank Johannes Kars, data specialist, and Dick van Blokland, ICU IT application specialist, for their support with data collection.

\begin{abstract}
Authors' contributions
All authors certify that they have participated sufficiently in the work to take public responsibility for the content, including participation in the concept, design, analysis, writing, or revision of the manuscript. Specific contributions are listed below. WK, YM, and AZ are responsible for the study concept and designing. WK, YM, and FZ are responsible for the acquisition of data. WK, $Y M$, and $A Z$ are responsible for the statistical analysis and interpretation of data. WK is responsible for the drafting of the manuscript. DD and AZ are responsible for the critical revision of the manuscript. All authors read and approved the final manuscript.
\end{abstract}

\section{Funding}

There was no funding source for this work.

\section{Availability of data and materials}

The datasets used and/or analyzed during the current study are available from the corresponding author on reasonable request.

\section{Ethics approval and consent to participate}

The institutional review board of Gelderse Vallei Hospital approved the study and waived informed consent for reasons of the retrospective design and anonymization of patient identifiers before analysis.

\section{Consent for publication}

Not applicable.

\section{Competing interests}

Arthur van Zanten reported that he has received honoraria for advisory board meetings, lectures, and travel expenses from Abbott, Baxter, BBraun, Danone-Nutricia, Fresenius Kabi, Mermaid, Lyric, and Nestle -Novartis. Inclusion fees for patients in nutrition trials were paid to the local ICU research foundation. The remaining authors declare that they have no competing interests.

\section{Author details}

${ }^{1}$ Department of Intensive Care Medicine, Gelderse Vallei Hospital, Willy Brandtlaan 10, 6716 RP Ede, The Netherlands. ${ }^{2}$ Department of Intensive Care Medicine, Diakonessenhuis Utrecht, Bosboomstraat 1, 3582 KE Utrecht, The Netherlands. ${ }^{3}$ Department of Intensive Care Medicine, Gelderse Vallei Hospital, University Medical Center Amsterdam, Willy Brandtlaan 10, 6716 RP Ede, The Netherlands. ${ }^{4}$ Department of Intensive Care Medicine, University Medical Centre Utrecht, Heidelberglaan 100, 3508 GA Utrecht, The Netherlands.
Received: 9 June 2019 Accepted: 16 January 2020

Published online: 03 February 2020

\section{References}

1. Zusman O, Theilla M, Cohen J, Kagan I, Bendavid I, Singer P. Resting energy expenditure, calorie and protein consumption in critically ill patients: a retrospective cohort study. Crit Care. 2016;20:367.

2. McClave $S$, Martindale $R$, Kiraly $L$. The use of indirect calorimetry in the intensive care unit. Curr Opin Clin Nutr Metab Care. 2013;16:202-8.

3. De Waele E, Spapen H, Honoré P, Mattens S, Van Gorp V, Diltoer M, et al. Introducing a new generation indirect calorimeter for estimating energy requirements in adult intensive care unit patients: Feasibility, practical considerations, and comparison with a mathematical equation. J Crit Care. 2013;28:884.e1-6.

4. Mooij CM, Beurskens CJ, Juffermans NP. Energy expenditure in different patient populations on intensive care: one size does not fit all. Neth J Crit Care. 2013;17:3-7

5. Menegueti M, de Araújo T, Laus A, Martins-Filho O, Basile-Filho A, Auxiliadora-Martins M. Resting energy expenditure and oxygen consumption in critically ill patients with vs without sepsis. Am J Crit Care 2019;28:136-41.

6. Subramaniam A, McPhee M, Nagappan R. Predicting energy expenditure in sepsis: Harris-Benedict and Schofield equations versus the Weir derivation. Crit Care Resusc. 2012:14:202-10.

7. Jeon J, Kym D, Cho YS, Kim Y, Yoon J, Yim H, Hur J, Chun W. Reliability of resting energy expenditure in major burns: comparison between measured and predictive equations. Clin Nutr. 2018; https://doi.org/10.1016/j.clnu.2018. 12.003.

8. Osuka A, Uno T, Nakanishi J, Hinokiyama H, Takahashi Y, Matsuoka T. Energy expenditure in patients with severe head injury: Controlled normothermia with sedation and neuromuscular blockade. J Crit Care. 2013;28:218.e9-218. e13.

9. Koukiasa P, Bitzani M, Papaioannou V, Pnevmatikos I. Resting energy expenditure in critically ill patients with spontaneous intracranial hemorrhage. JPEN J Parenter Enteral Nutr. 2014;39:917-21.

10. Berggren E, O'Tierney-Ginn P, Lewis S, Presley L, De-Mouzon S, Catalano P. Variations in resting energy expenditure: impact on gestational weight gain. Am J Obstet Gynecol. 2017;217:445.e1-6.

11. Terao Y, Miura K, Saito M, Sekino M, Fukusaki M, Sumikawa K. Quantitative analysis of the relationship between sedation and resting energy expenditure in postoperative patients. Crit Care Med. 2003:31:830-3.

12. Holzinger $U$, Brunner $R$, Losert $H$, Fuhrmann $V$, Herkner $H$, Madl $C$, et al. Resting energy expenditure and substrate oxidation rates correlate to temperature and outcome after cardiac arrest - a prospective observational cohort study. Crit Care. 2015;19:128

13. Murray M, DeBlock H, Erstad B, Gray A, Jacobi J, Jordan C, et al. Clinical practice guidelines for sustained neuromuscular blockade in the adult critically ill patient. Crit Care Med. 2016:44:2079-103.

14. Kagan I, Zusman O, Bendavid I, Theilla M, Cohen J, Singer P. Validation of carbon dioxide production (VCO2) as a tool to calculate resting energy expenditure (REE) in mechanically ventilated critically ill patients: a retrospective observational study. Crit Care. 2018;22:186.

15. Stapel S, de Grooth H, Alimohamad H, Elbers P, Girbes A, Weijs P, et al. Ventilator-derived carbon dioxide production to assess energy expenditure in critically ill patients: proof of concept. Crit Care. 2015;19:370.

16. Oshima T, Graf S, Heidegger CP, Genton L, Pugin J, Pichard C. Can calculation of energy expenditure based on $\mathrm{CO} 2$ measurements replace indirect calorimetry? Crit Care. 2017;21:13.

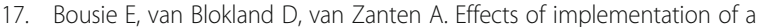
computerized nutritional protocol in mechanically ventilated critically ill patients: a single-centre before and after study. Clin Nutr ESPEN. 2016;11: e47-54.

18. Elia M. Insights into energy requirements in disease. Public Health Nutr. 2005:8:1037-52

19. Charlson M, Pompei $P$, Ales $K$, MacKenzie C. A new method of classifying prognostic comorbidity in longitudinal studies: development and validation. J Chronic Dis. 1987;40:373-83.

20. Rahman A, Hasan R, Agarwala R, Martin C, Day A, Heyland D. Identifying critically-ill patients who will benefit most from nutritional therapy: further validation of the "modified NUTRIC" nutritional risk assessment tool. Clin Nutr. 2016;35:158-62. 
21. Szakmany T, Woodhouse T. Use of cisatracurium in critical care: a review of the literature. Minerva Anestesiol. 2015;81:450-60.

22. McCall M, Jeejeebhoy K, Pencharz P, Moulton R. Effect of neuromuscular blockade on energy expenditure in patients with severe head injury. JPEN J Parenter Enteral Nutr. 2003;27:27-35.

23. Vernon $D$, Witte M. Effect of neuromuscular blockade on oxygen consumption and energy expenditure in sedated, mechanically ventilated children. Crit Care Med. 2000;28:1569-71.

24. Manthous CA, Hall JB, Olson D, Singh M, Chatila W, Pohlman A, et al. Effect of cooling on oxygen consumption in febrile critically ill patients. Am J Respir Crit Care Med. 1995;151:10-4.

25. Tokutomi T, Morimoto K, Miyagi T, Yamaguchi S, Ishikawa K, Shigemori M. Optimal temperature for the management of severe traumatic brain injury: effect of hypothermia on intracranial pressure, systemic and intracranial hemodynamics, and metabolism. Neurosurgery. 2003;52:102-11.

26. National Heart, Lung, and Blood Institute PETAL Clinical Trials Network, Moss M, Huang DT, Brower RG, Ferguson ND, Ginde AA, Gong MN, Grissom CK, Gundel S, Hayden D, Hite RD, Hou PC, Hough CL, Iwashyna TJ, Khan A, Liu KD, Talmor D, Thompson BT, Ulysse CA, Yealy DM, Angus DC. Early neuromuscular blockade in the acute respiratory distress syndrome. $\mathrm{N} \mathrm{Engl}$ J Med. 2019;380(21):1997-2008. https://doi.org/10.1056/NEJMoa1901686. Epub 2019 May 19]

27. Papazian L, Forel JM, Gacouin A, Penot-Ragon C, Perrin G, Loundou A, Jaber S, Arnal JM, Perez D, Seghboyan JM, Constantin JM, Courant P, Lefrant JY, Guérin C, Prat G, Morange S, Roch A, ACURASYS Study Investigators. Neuromuscular blockers in early acute respiratory distress syndrome. N Engl J Med. 2010;363(12):1107-16. https://doi.org/10.1056/NEJMoa1005372.

\section{Publisher's Note}

Springer Nature remains neutral with regard to jurisdictional claims in published maps and institutional affiliations.

Ready to submit your research? Choose BMC and benefit from:

- fast, convenient online submission

- thorough peer review by experienced researchers in your field

- rapid publication on acceptance

- support for research data, including large and complex data types

- gold Open Access which fosters wider collaboration and increased citations

- maximum visibility for your research: over $100 \mathrm{M}$ website views per year

At $\mathrm{BMC}$, research is always in progress.

Learn more biomedcentral.com/submissions 